\title{
Risk factors for recurrence of Crohn's disease requiring surgery in patients receiving post-operative anti-tumor necrosis factor maintenance therapy
}

\author{
Toshimitsu Araki, Yoshiki Okita, Satoru Kondo, Junichiro Hiro, Yuji Toiyama, Mikihiro Inoue, \\ Masaki Ohi, Yasuhiro Inoue, Keiichi Uchida, Yasuhiko Mohri and Masato Kusunoki \\ Department of Gastrointestinal and Pediatric Surgery, Division of Reparative Medicine, \\ Institute of Life Sciences, Mie University Graduate School of Medicine, Mie, Japan
}

\begin{abstract}
:
Objectives: Anti-tumor necrosis factor (TNF) antibodies have shown efficacy in the prevention of recurrence of Crohn's disease after intestinal resection. However, some patients develop surgical recurrence despite this therapy. We aimed to evaluate the risk factors for recurrence of Crohn's disease requiring surgery while receiving post-operative anti-TNF therapy. Methods: We performed a retrospective evaluation of 164 patients who had received post-operative anti-TNF maintenance therapy between 2002 and 2016. We classified Crohn's disease-related re-operation as surgical recurrence and analyzed its risk factors using the Cox proportional hazard model. Results: Of the 164 participants, 128 had received infliximab and 36 had received adalimumab maintenance therapy. We obtained follow-up data over a mean of 60.2 months. The proportion of patients with surgical recurrence at 5 years was $14.9 \%$. The only independent risk factor for surgical recurrence, which we identified was post-operative smoking habit (odds ratio, 5.03; 95\% CI, 1.1412.8; $\mathrm{P}=0.033$ ). Conclusions: Post-operative smoking may be a significant risk factor for post-operative surgical recurrence of Crohn's disease while receiving anti-TNF maintenance therapy.
\end{abstract}

Keywords:

Crohn's disease, operation, recurrence, anti-TNF therapy, smoking

J Anus Rectum Colon 2017; 1(1): 15-21

\section{Introduction}

Crohn's disease $(\mathrm{CD})$, a chronic, lifelong, inflammatory bowel disorder, is characterized by repeated relapse and remission; and most patients require bowel resections ${ }^{1,22}$. Resection of the affected intestine is the ultimate option for refractory segmental $\mathrm{CD}$ and the requirement for further surgery remains the most objective endpoint in studies regarding disease recurrence. Without further treatment, 25 to $30 \%$ of post-operative patients with $\mathrm{CD}$ will require further surgery by 5 years $^{3}$. Thus, post-operative recurrence of CD is an important management challenge. In recent years, antitumor necrosis factor (TNF) antibodies, namely infliximab (IFX) and adalimumab (ADA), have shown efficacy in the prevention of $\mathrm{CD}$ after intestinal resection ${ }^{4.7)}$. We have previously reported that post-operative IFX maintenance therapy reduces the incidence of surgical recurrence of $\mathrm{CD}^{8)}$.
However, some patients do develop surgical recurrence despite post-operative anti-TNF antibodies maintenance therapy. Therefore, this retrospective study aimed to evaluate the risk factors for surgical recurrence of $\mathrm{CD}$ in patients receiving post-operative anti-TNF antibody maintenance therapy.

\section{Methods}

All patients in our institution's database with CD who had undergone bowel resection at Mie University Hospital between May 2002 and February 2016 were considered for inclusion in this retrospective study. A total of 180 patients underwent $247 \mathrm{CD}$ surgeries during the study period. The 164 cases (146 patients, including 16 patients with two operations and 1 patient with three operations) who had received post-operative anti-TNF antibody maintenance therapies from within 6 months of primary surgery were included 
in the present analysis.

Diagnoses of CD were based on clinical, radiographic, endoscopic, and pathological data and had been established according to the accepted criteria, ${ }^{9,10)}$, the Montreal classification being used to assess the behavior, severity, extent, and location of disease ${ }^{11}$.

All patients provided written informed consent for using their data in this study. The study was conducted in accordance with the Declaration of Helsinki and approved by the Institutional Review Board.

Indications for post-operative anti-TNF antibody maintenance therapy were considered as a high risk of $\mathrm{CD}$ recurrence because of having undergone multiple operations within a short period, requiring early surgery despite aggressive medical treatment, or having a longer than usual portion of bowel being affected. With regard to the selection of an anti-TNF antibody, patients who had been receiving antiTNF antibodies prior to surgery were prescribed the previously administered drug as soon as possible. Anti-TNF antibody-naïve patients chose between IFX and ADA themselves after receiving an explanation that large clinical trials comparing both these agents found similar efficacy in induction and maintenance of remission for patients with moderate to severe $\mathrm{CD}$, and adverse effects of these drugs are also comparable. The previously unused anti-TNF antibody was selected for post-operative therapy in patients with a history of episodic administration or long breaks from an anti-TNF antibody.

The induction phase for IFX was defined as the administration of a standard regimen of three IFX infusions $(5 \mathrm{mg} /$ $\mathrm{kg})$ at 0,2 , and 6 weeks, and subsequent maintenance infusions $(5 \mathrm{mg} / \mathrm{kg})$ every 8 weeks. Patients with loss of response (LOR) to $5 \mathrm{mg} / \mathrm{kg}$ of IFX had their dose escalated to $10 \mathrm{mg} / \mathrm{kg}$. ADA induction was with subcutaneous injections of $160 \mathrm{mg}$ in week $0,80 \mathrm{mg}$ in week 2 , and then $40 \mathrm{mg}$ every other week. Patients showing LOR to $40 \mathrm{mg}$ every other week of ADA had their doses escalated to $40 \mathrm{mg}$ every week. Patients who did not tolerate IFX (i.e., by infusion reactions) were switched to ADA.

The following characteristics were recorded for all participants: Gender, age, and disease location and behavior at diagnosis (Montreal classification) ${ }^{11)}$, age, strictureplasty, ileocecal resection, presence of anal lesions at operation, smoking habit after primary surgery, and post-operative concomitant use of thiopurine and an elemental diet. The primary outcome event was defined as re-operation for $\mathrm{CD}$ recurrence, confirmation of such recurrence being based on pathological examination of the resected specimen.

Statistical analysis was performed using IBM SPSS statistics ver. 22 (IBM). Surgical recurrence-free survival was calculated as the time from the date of primary operation to the date of re-operation or last follow-up. Univariate analysis of the probability of re-operation-free survival was performed by the Kaplan-Meier method and the risk of CD-related reoperation was analyzed by the Cox proportional hazard model. A $P$ value of less than 0.05 was considered signifi- cant.

\section{Results}

A total of 112 initial operations and 52 re-operations was included in the 164 cases. Anti-TNF antibody maintenance therapy comprised IFX in 128 cases and ADA in 36 cases (including 10 patients who did not tolerate IFX and were switched to ADA). Relevant baseline characteristics are shown in Table 1. Follow-up data were obtained over a mean of 60.2 months (range 8-206 months). By the end of follow-up, 18 patients had required re-operation while receiving post-operative anti-TNF antibody maintenance therapy. The percentages of patients with surgical recurrence at $1,3,5$, and 10 years were $1.3 \%, 5.9 \%, 14.9 \%$, and $16.7 \%$, respectively (Figure 1).

Results of univariate analysis of factors associated with surgical recurrence after intestinal resection for $\mathrm{CD}$ are shown in Table 2. The only independent risk factor significantly associated with surgical recurrence was post-operative smoking habit (odds ratio, 5.03; 95\% CI, 1.14-12.8; $\mathrm{P}=$ 0.033 ) (Figure 2). There was a non-significant tendency for surgical recurrence to occur more frequently in patients without large intestinal involvement (Montreal L1) (odds ratio, 2.38; 95\% CI, 0.94-6.05; P=0.068) (Figure 3).

\section{Discussion}

Post-operative recurrence of intestinal CD can be defined as endoscopic, histological, clinical, radiological, or surgical. Anti-TNF antigens have recently been shown to be effective in preventing endoscopic and clinical recurrence of CD. In a randomized, placebo-controlled study conducted over 1 year, Regueiro et al. ${ }^{4}$ reported that administration of IFX after bowel resection was effective in reducing the incidence of endoscopic (9.1\% vs. 84.6\%, $\mathrm{P}=0.0006)$ and histological ( $27.3 \%$ vs. $84.6 \%, \mathrm{P}=0.01)$ recurrence of $\mathrm{CD}$. Savarino et al. $\left.{ }^{6}\right)$ have reported that post-operative ADA is also effective. In their prospective, open-label, randomized trial with a 2year follow-up, they found significantly lower rates of endoscopic and clinical recurrence in patients receiving ADA $(6.3 \%$ and $12.5 \%$, respectively) than in those receiving azathioprine $(64.7 \%$ and $64.7 \%$, respectively) or mesalazine ( $83.3 \%$ and $50 \%$, respectively).

In a retrospective direct comparison between IFX and ADA therapy after ileocecal resection, there was no significant difference between the two anti-TNF agents in terms of early post-operative endoscopic recurrence rates (12\% vs. $32 \%, \quad \mathrm{P}=0.815)^{12}$. With regard to surgical recurrence, Regueiro et al. ${ }^{13)}$ reported a prospective, open-label study with follow-up for at least 5 years after surgery: They found a significantly lower surgical recurrence rate in patients who had received IFX during most of the follow-up than in patients who had received it for shorter periods $(20.0 \%$ vs. $64.3 \%, \mathrm{P}=0.047$ ). Our previous retrospective case-control study showed a lower incidence of surgical recurrence of 
Table 1. Clinical Characteristics of Patients with Crohn's Disease Receiving Post-operative Anti-TNF Antibody Maintenance Therapy.

\begin{tabular}{|c|c|c|}
\hline \multicolumn{2}{|l|}{ Variable } & \multirow{2}{*}{$\begin{array}{l}\mathrm{N}=164(\%) \\
120(73.2)\end{array}$} \\
\hline Gender & Male & \\
\hline & Female & $44(26.8)$ \\
\hline Age at primary operation (years) & & 35.5 (range 14-65) \\
\hline \multirow[t]{2}{*}{ Age at diagnosis } & $\leq 40 \mathrm{yrs}$ & $149(90.9)$ \\
\hline & $>40 \mathrm{yrs}$ & $15(9.1)$ \\
\hline \multirow[t]{3}{*}{ Disease location } & Terminalileum & $61(37.2)$ \\
\hline & Colon & $17(10.4)$ \\
\hline & Ileum and colon & $86(52.4)$ \\
\hline \multirow[t]{3}{*}{ Disease behavior } & Non-stricturing & $4(2.4)$ \\
\hline & Stricturing & $80(48.8)$ \\
\hline & Penetrating & $80(48.8)$ \\
\hline \multirow[t]{2}{*}{ Presence of anal lesions } & Yes & $71(43.3)$ \\
\hline & No & $93(56.7)$ \\
\hline \multirow[t]{2}{*}{ Type of operation } & Initial surgery & $112(68.3)$ \\
\hline & Reoperation & $52(31.7)$ \\
\hline \multirow[t]{2}{*}{ Ileocecal resection only } & Yes & $16(90.2)$ \\
\hline & No & $148(9.8)$ \\
\hline \multirow[t]{2}{*}{ Strictureplasty } & Yes & $26(15.9)$ \\
\hline & No & $138(84.1)$ \\
\hline \multirow[t]{2}{*}{ Post-operative smoking habit } & Yes & $6(3.7)$ \\
\hline & No & $158(96.3)$ \\
\hline \multirow[t]{2}{*}{ Post-operative thiopurine use } & Yes & $34(20.7)$ \\
\hline & No & $130(79.3)$ \\
\hline \multirow[t]{2}{*}{ Post-operative elemental diet use } & Yes & $57(34.8)$ \\
\hline & No & $107(65.2)$ \\
\hline
\end{tabular}

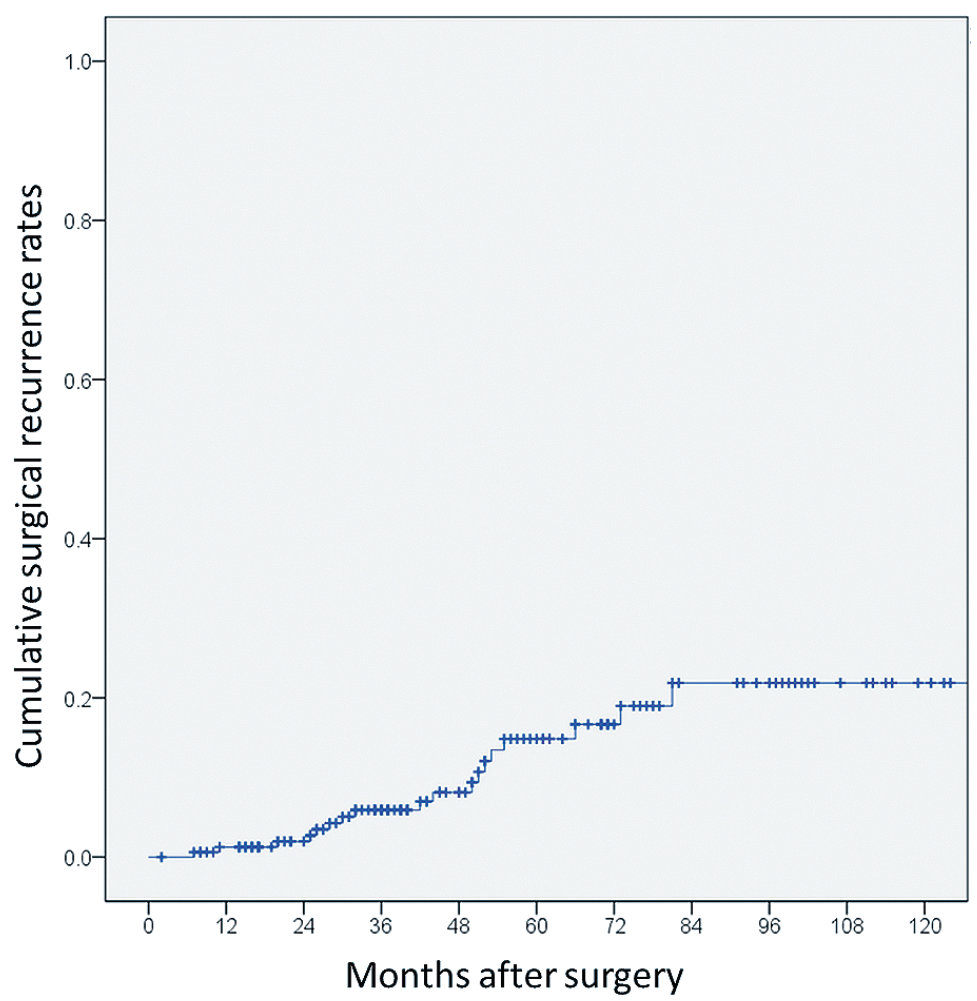

Figure 1. Kaplan-Meier plots illustrating cumulative surgical recurrence rates in patients with Crohn's disease receiving post-operative anti-TNF maintenance therapy. 
Table 2. Results of Univariate Analysis of Factors Associated with Surgical Recurrence after Intestinal Resection for Crohn's Disease in Patients Receiving Post-operative Anti-TNF Maintenance Therapy.

\begin{tabular}{|c|c|c|c|}
\hline Variable & OR & $95 \% \mathrm{CI}$ & $\mathrm{P}$ \\
\hline $\begin{array}{r}\text { Gender } \\
\mathrm{M} / \mathrm{F}\end{array}$ & 2.04 & $0.59-7.09$ & 0.259 \\
\hline $\begin{array}{l}\text { Age at primary surgery } \\
<40 \text { years } / \geq 40 \text { years }\end{array}$ & 1.65 & $0.25-12.5$ & 0.657 \\
\hline $\begin{array}{l}\text { Age at diagnosis } \\
<40 \text { years }>40 \text { years }\end{array}$ & 1.23 & $0.47-3.44$ & 0.628 \\
\hline $\begin{array}{l}\text { Post-operative smoking } \\
\text { Yes/No }\end{array}$ & 5.03 & $1.14-22.2$ & 0.033 \\
\hline $\begin{array}{l}\text { Small intestinal involvement } \\
\text { Yes/No }\end{array}$ & 2.38 & $0.026-40.5$ & 0.361 \\
\hline $\begin{array}{l}\text { Large intestinal involvement } \\
\mathrm{No} / \mathrm{Yes}\end{array}$ & 2.38 & $0.01-37.4$ & 0.068 \\
\hline $\begin{array}{l}\text { Multiple stenoses in small intestine } \\
\text { No/Yes }\end{array}$ & 1.23 & $0.41-3.75$ & 0.713 \\
\hline $\begin{array}{l}\text { Disease behavior } \\
\text { Non-penetrating/Penetrating }\end{array}$ & 1.34 & $0.53-3.45$ & 0.534 \\
\hline $\begin{array}{l}\text { Perianal disease } \\
\text { No/Yes }\end{array}$ & 1.13 & $0.45-2.87$ & 0.797 \\
\hline $\begin{array}{l}\text { Type of operation } \\
\text { Reoperation/Initial surgery }\end{array}$ & 1.21 & $0.47-3.12$ & 0.696 \\
\hline $\begin{array}{l}\text { Strictureplasty } \\
\text { Yes/No }\end{array}$ & 1.60 & $0.56-5.24$ & 0.343 \\
\hline $\begin{array}{l}\text { Ileocecal resection only } \\
\qquad \mathrm{No} / \mathrm{Yes}\end{array}$ & 1.70 & $0.23-12.8$ & 0.608 \\
\hline $\begin{array}{l}\text { Receiving elemental diet } \\
\text { Yes/No }\end{array}$ & 2.28 & $0.90-5.77$ & 0.082 \\
\hline $\begin{array}{l}\text { Thiopurine use } \\
\text { Yes/No }\end{array}$ & 1.12 & $0.40-3.15$ & 0.831 \\
\hline
\end{tabular}

Cox proportional hazard model

$\mathrm{CD}$ in patients receiving post-operative IFX maintenance therapy than in control patients at 36 months follow-up (6.0\% vs. $68.0 \%, \mathrm{P}=0.002)$. In addition, in this retrospective study, the cumulative rates of surgical recurrence while receiving post-operative anti-TNF antibody maintenance therapy were $5.9 \%$ and $14.9 \%$ at 3 and 5 years follow-up, respectively. These data indicate that post-operative anti-TNF antibody maintenance therapy is highly effective in minimizing surgical recurrence of $\mathrm{CD}$; however, this treatment is ineffective in some patients.

In this study, we found that post-operative smoking was a significant risk factor for post-operative surgical recurrence of $\mathrm{CD}$ while receiving maintenance therapy with anti-TNF antibodies. Previous studies have shown that smoking is both a risk factor for relapse of $\mathrm{CD}$ in general and for surgical recurrence in particular ${ }^{14-17)}$. A recent multicenter prospective cohort study showed that despite the widespread use of immunosuppressants and anti-TNF antibodies, smokers with $\mathrm{CD}$ have a more severe disease course, including greater requirements for treatment, than non-smokers ${ }^{18)}$. Furthermore, a retrospective study conducted to evaluate the effects of smoking at diagnosis on the clinical outcomes after endoscopic dilation found that smoking doubles the risk of recurrent stricture formation requiring further intestinal resection or strictureplasty. Maintenance therapy with azathioprine did not influence the subsequent course or the need for new interventions ${ }^{19)}$.

Our current data support the finding that smoking habit adversely affects the risk of recurrence despite anti-TNF maintenance therapy.

On the other hand, evidence for routine use of azathioprine in post-operative patients with $\mathrm{CD}$ is not definitive $\mathrm{e}^{20,21)}$. ADA has been shown to be superior to thiopurines in preventing early post-operative $\mathrm{CD}$ recurrence in high-risk patients $^{22}$. Moreover, several studies have shown that elemental diet therapy is effective in minimizing endoscopic recurrence $^{23)}$ and reducing the incidence of second resections ${ }^{24,25)}$.

However, we found no association between concomitant use of azathioprine or elemental diet and surgical recurrence. Because the indications for use of these concomitant drugs were not standardized, there is probably some bias in the present data. Our findings should, therefore, be assessed 


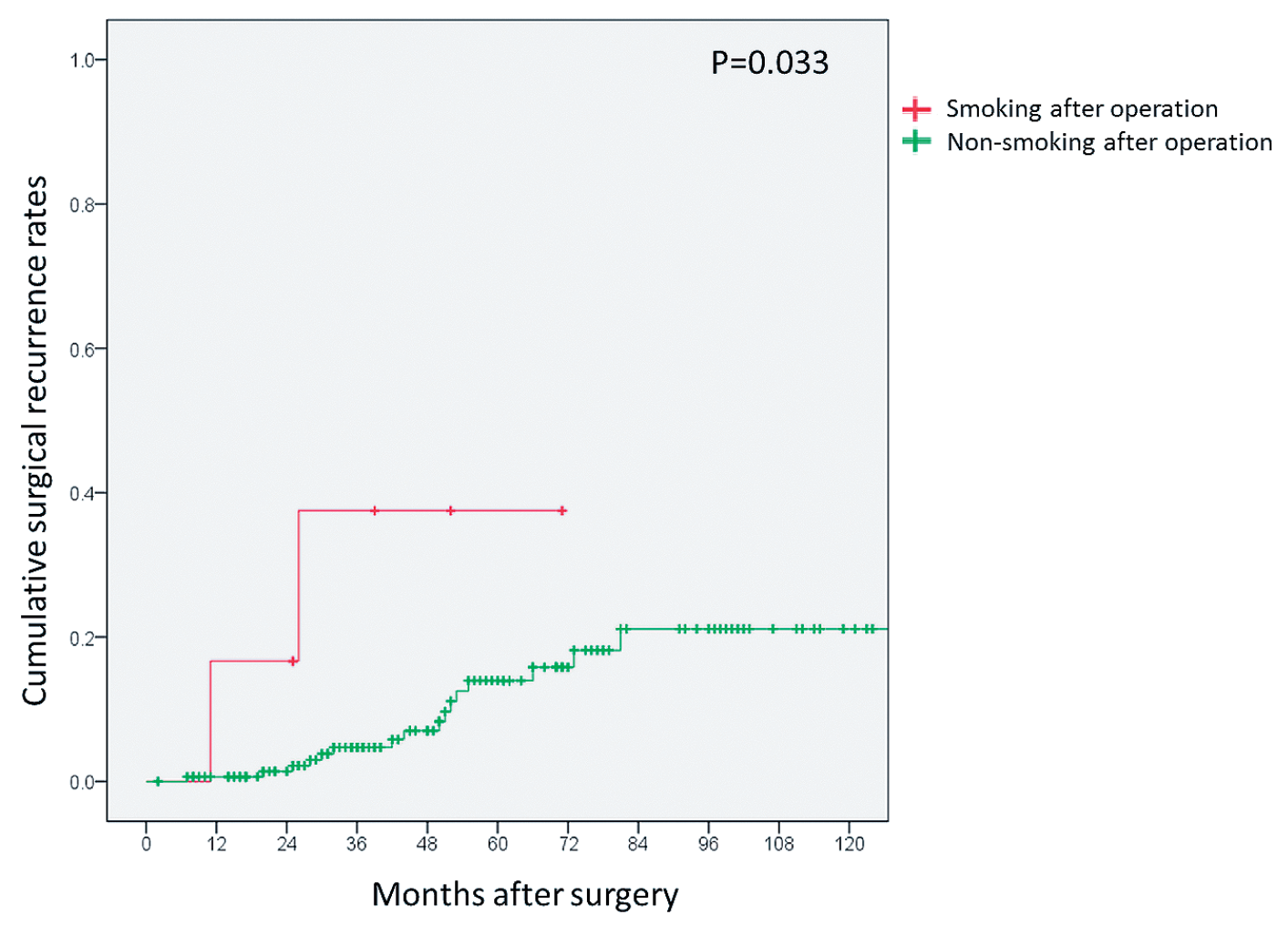

Figure 2. Kaplan-Meier plots illustrating cumulative surgical recurrence rates of Crohn's disease in patients receiving post-operative anti-TNF maintenance therapy grouped by post-operative smoking or nonsmoking. Post-operative smoking habit was an independent risk factor for surgical recurrence (odds ratio, 5.03; 95\% CI, 1.14-12.8; $\mathrm{P}=0.033$ ).

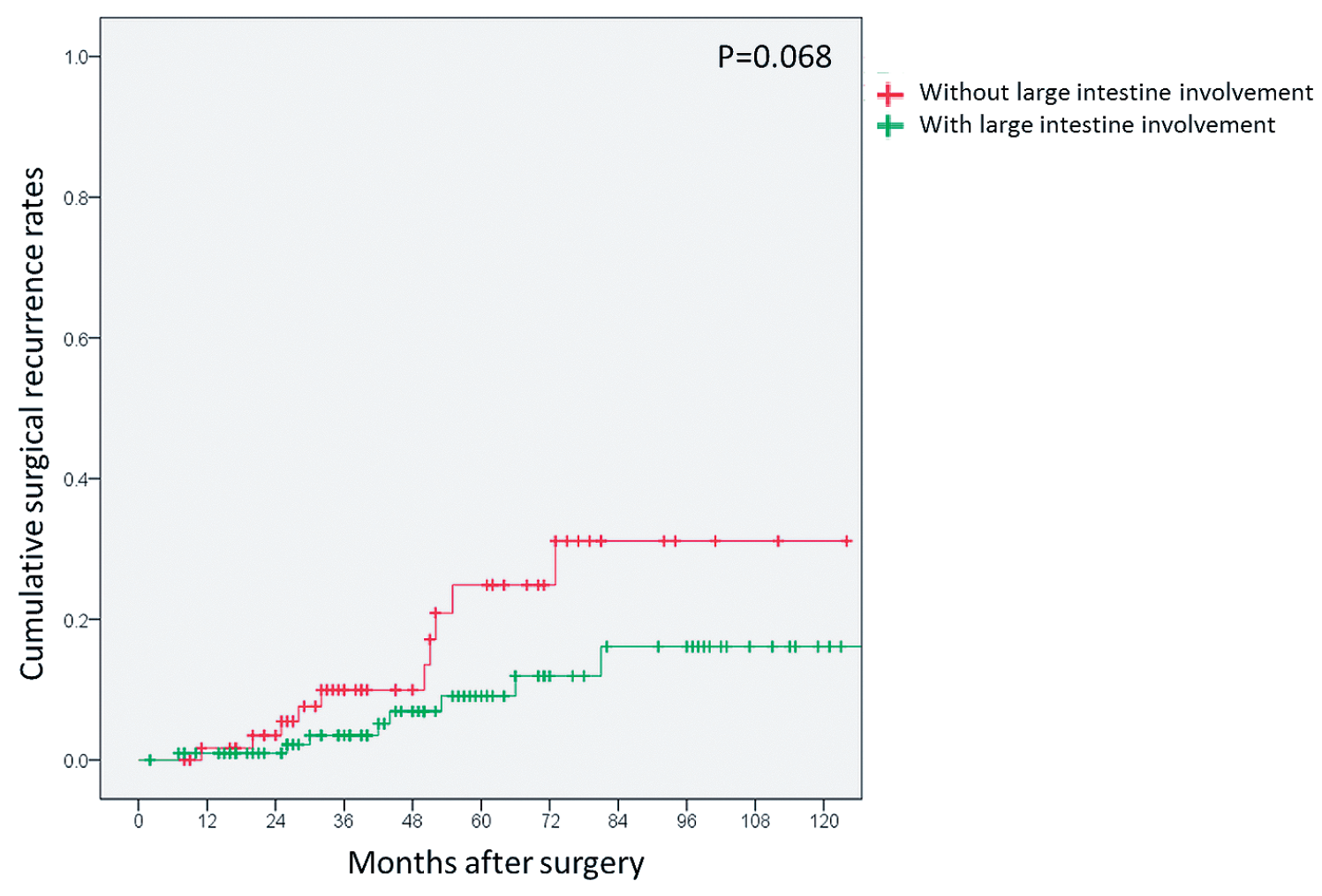

Figure 3. Kaplan-Meier plots illustrating cumulative surgical recurrence rates in patients with Crohn's disease who received post-operative anti-TNF maintenance therapy grouped by presence or not of large intestinal involvement. There was a non-significant tendency toward higher rates of surgical recurrence in patients without large intestinal involvement (Montreal L1) (odds ratio, 2.38; 95\% CI, 0.94-6.05; P=0.068). 
by further controlled studies.

In this study, we identified a non-significant tendency for surgical recurrence of $\mathrm{CD}$ to occur in patients without large intestinal involvement, that is, with ileal disease (Montreal L1), despite anti-TNF maintenance therapy. Recurrence after resection is considered to occur more frequently with small bowel disease, as previously stated ${ }^{26}$. In addition, several studies have shown that the extent of ileal involvement is a predictor of early post-operative recurrence ${ }^{27,28)}$. Likewise, ileal disease location is a significant risk factor for a second ileocolic resection ${ }^{29)}$. Although, our data did not confirm that small intestinal involvement is a significant risk factor for surgical recurrence of $\mathrm{CD}$ while receiving post-operative anti-TNF maintenance therapy, CD limited to the small intestine should probably be managed by more aggressive post-operative therapy.

\section{Conclusion}

Post-operative smoking may be a significant risk factor for post-operative surgical recurrence of patients with $\mathrm{CD}$ receiving maintenance therapy with anti-TNF antibodies. Although further larger studies are necessary to assess this apparent disadvantage, we believe that all high-risk patients with $\mathrm{CD}$ should be encouraged to quit smoking after surgery.

\section{Conflicts of Interest}

The authors declare that there are no conflict of interest.

\section{References}

1. Sachar DB. The problem of postoperative recurrence of Crohns disease. Med Clin North Am. 1990 Jan;74(1):183-8.

2. Mekhjian HS, Switz DM, Watts HD, et al. National Cooperative Crohn's Disease Study: factors determining recurrence of Crohn's disease after surgery. Gastroenterology. 1979 Oct;77(4 Pt 2):90713.

3. Ramadas AV, Gunesh S, Thomas GA, et al. Natural history of Crohn's disease in a population-based cohort from Cardiff (19862003): a study of changes in medical treatment and surgical resection rates. Gut. 2010 Sep;59(9):1200-6.

4. Regueiro M, Schraut W, Baidoo L, et al. Infliximab prevents Crohn's disease recurrence after ileal resection. Gastroenterology. 2009 Feb;136(2):441-50.

5. Sorrentino D, Paviotti A, Fiorino G. Anti-TNF's for postoperative recurrence in Crohn's disease: the if's and how's. Curr Drug Targets. $2010 \mathrm{Feb}$;11(2):219-26.

6. Savarino E, Bodini G, Dulbecco P, et al. Adalimumab is more effective than azathioprine and mesalamine at preventing postoperative recurrence of Crohn's disease: a randomized controlled trial. Am J Gastroenterol. 2013 Nov;108(11):1731-42.

7. De Cruz P, Kamm MA, Hamilton AL, et al. Crohn's disease management after intestinal resection: a randomised trial. Lancet. Apr 11;385(9976):1406-17.

8. Araki T, Uchida K, Okita Y, et al. Impact of postoperative infliximab maintenance therapy on preventing the surgical recurrence of Crohn's disease: a single-center paired case-control study. Surg Today. 2014 Feb;44(2):291-6.

9. Ueno F, Matsui T, Matsumoto $T$, et al. Evidence-based clinical practice guidelines for Crohn's disease, integrated with formal consensus of experts in Japan. J Gastroenterol. 2013 Jan;48(1):3172.

10. Van Assche G, Dignass A, Panes J, et al. The second European evidence-based Consensus on the diagnosis and management of Crohn's disease: definitions and diagnosis. J Crohns Colitis. 2010 Feb;4(1):7-27.

11. Satsangi J, Silverberg MS, Vermeire S, et al. The Montreal classification of inflammatory bowel disease: controversies, consensus, and implications. Gut. 2006 Jun;55(6):749-53.

12. Kotze PG, Yamamoto T, Danese $S$, et al. Direct retrospective comparison of adalimumab and infliximab in preventing early postoperative endoscopic recurrence after ileocaecal resection for Crohn's disease: results from the MULTIPER database. J Crohns Colitis. 2015 Jul;9(7):541-7.

13. Regueiro M, Kip KE, Baidoo L, et al. Postoperative therapy with infliximab prevents long-term Crohn's disease recurrence. Clin Gastroenterol Hepatol. 2014 Sep;12(9):1494-502.

14. Duffy LC, Zielezny MA, Marshall JR, et al. Cigarette smoking and risk of clinical relapse in patients with Crohn's disease. Am J Prev Med. 1990 May-Jun;6(3):161-6.

15. Medina $C$, Vergara $M$, Casellas $F$, et al. Influence of the smoking habit in the surgery of inflammatory bowel disease. Rev Esp Enferm Dig. 1998 Nov;90(11):771-8.

16. Lunney PC, Kariyawasam VC, Wang RR, et al. Smoking prevalence and its influence on disease course and surgery in Crohn's disease and ulcerative colitis. Aliment Pharmacol Ther. 2015 Jul; 42(1):61-70.

17. Ryan WR, Allan RN, Yamamoto T, et al. Crohn's disease patients who quit smoking have a reduced risk of reoperation for recurrence. Am J Surg. 2004 Feb;187(2):219-25.

18. Nunes T, Etchevers MJ, Domenech E, et al. Smoking does influence disease behaviour and impacts the need for therapy in Crohn's disease in the biologic era. Aliment Pharmacol Ther. 2013 Oct;38(7):752-60.

19. Gustavsson A, Magnuson A, Blomberg B, et al. Smoking is a risk factor for recurrence of intestinal stricture after endoscopic dilation in Crohn's disease. Aliment Pharmacol Ther. 2013 Feb;37(4):4307.

20. Papay P, Reinisch W, Ho E, et al. The impact of thiopurines on the risk of surgical recurrence in patients with Crohn's disease after first intestinal surgery. Am J Gastroenterol. 2010 May;105(5): 1158-64.

21. Jones GR, Kennedy NA, Lees CW, et al. Systematic review: the use of thiopurines or anti-TNF in post-operative Crohn's disease maintenance-progress and prospects. Aliment Pharmacol Ther. 2014 Jun;39(11):1253-65.

22. De Cruz P, Kamm MA, Hamilton AL, et al. Efficacy of thiopurines and adalimumab in preventing Crohn's disease recurrence in high-risk patients: a POCER study analysis. Aliment Pharmacol Ther. 2015 Oct;42(7):867-79.

23. Yamamoto $\mathrm{T}$, Nakahigashi $\mathrm{M}$, Umegae $\mathrm{S}$, et al. Impact of longterm enteral nutrition on clinical and endoscopic recurrence after resection for Crohn's disease: a prospective, non-randomized, parallel, controlled study. Aliment Pharmacol Ther. 2007 Jan;25(1): 67-72.

24. Ikeuchi H, Yamamura T, Nakano H, et al. Efficacy of nutritional therapy for perforating and non-perforating Crohn's disease. Hepatogastroenterology. 2004 Jul-Aug;51(58):1050-2.

25. Yamamoto T, Shiraki M, Nakahigashi M, et al. Enteral nutrition to suppress postoperative Crohn's disease recurrence: a five-year prospective cohort study. Int J Colorectal Dis. 2013 Mar;28(3):335- 
40.

26. Rutgeerts P, Geboes K, Vantrappen G, et al. Predictability of the postoperative course of Crohn's disease. Gastroenterology. 1990 Oct;99(4):956-63.

27. Bernell O, Lapidus A, Hellers G. Risk factors for surgery and recurrence in 907 patients with primary ileocaecal Crohn's disease. Br J Surg. 2000 Dec;87(12):1697-701.

28. Welsch T, Hinz U, Loffler T, et al. Early re-laparotomy for postoperative complications is a significant risk factor for recurrence after ileocaecal resection for Crohn's disease. Int J Colorectal Dis.
2007 Sep;22(9):1043-9.

29. Manser CN, Frei P, Grandinetti T, et al. Risk factors for repetitive ileocolic resection in patients with Crohn's disease: results of an observational cohort study. Inflamm Bowel Dis. 2014 Sep;20(9): 1548-54.

Journal of the Anus, Rectum and Colon is an Open Access article distributed under the Creative Commons Attribution-NonCommercial-NoDerivatives 4.0 International License. To view the details of this license, please visit (https://creativecommons.org/licenses/by-nc-nd/4.0/). 